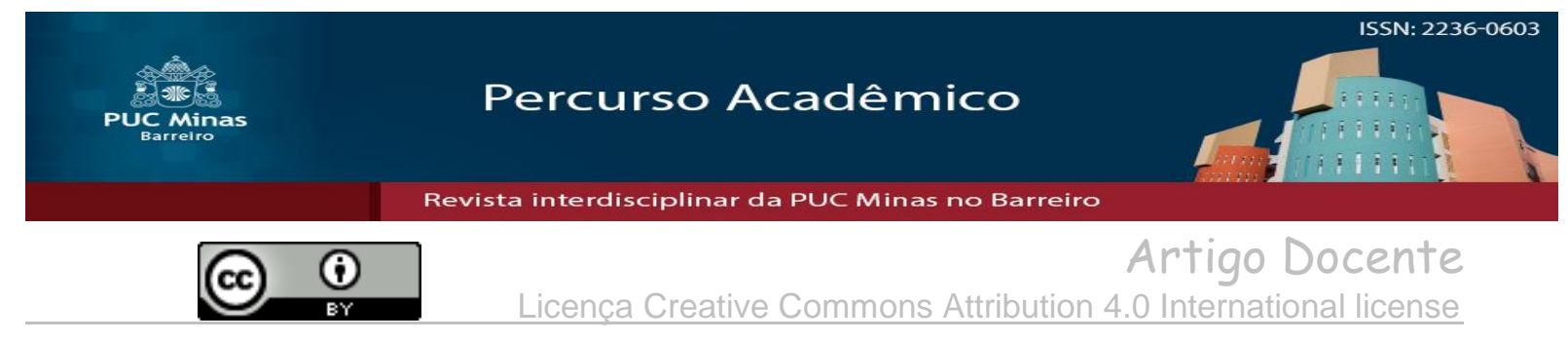

\title{
Algumas reflexões psicanalíticas sobre o fazer pedagógico de professores da educação infantil a partir do referencial curricular nacional para educação infantil e outros documentos
}

\author{
Some Psychoanalytic reflections on the pedagogical practice of \\ professionals involved with children's education based upon \\ National Leaning Guidelines and other documents.
}

\author{
Viviane Marques Alvim Campi Barbosa ${ }^{1}$ \\ Nádia Laguárdia de Lima²
}

\begin{abstract}
Resumo
O presente artigo busca refletir sobre a prática dos professores junto às crianças pequenas de zero a três anos de idade, nas instituições de Educação Infantil. Para fazer essa reflexão utiliza a teoria psicanalítica. O percurso teórico parte das representações de professor que sustenta os referenciais e as diretrizes para a Educação Infantil, para em seguida analisar se os seus parâmetros favorecem ou não o trabalho do educador de apoio à subjetivação dos bebês e crianças pequenas. Considera-se que o trabalho do professor com bebês e crianças pequenas nas instituições não se restringe à aplicação de técnicas ou à execução de currículos prescritos, tampouco consiste em tomar as crianças como um corpo a ser higienizado, alimentado e protegido. Os referenciais e diretrizes para a educação infantil apresentam-se como uma maneira de regular e disciplinar a atuação dos profissionais da educação infantil, a fim de que seja garantido à criança o seu desenvolvimento integral. Entretanto, este artigo defende a hipótese de que o papel do educador não deveria estar referido a um padrão universal, mas caminhar no sentido da singularização das crianças.

Palavras chave: Bebês. Crianças pequenas. Educação infantil. Referencial Curricular Nacional para a Educação Infantil. Diretrizes para a Educação Infantil.
\end{abstract}

\begin{abstract}
In the present article, we reflect on the practice of teachers in schools for children between the ages 0-3 years old. This is done within the framework of Psychoanalytic Theory. Starting from the teacher's representations which support Infants and Toddlers Learning Guidelines, we analyze whether its parameters do or do not favor the work of support educators towards the subjectivation of infants and toddlers. It is considered by the authors that the work of support educators with these small children does not restrict neither to the application of prescribed guidelines nor consists in thinking of the child only as a body in need of being fed, cleaned, and protected. The Learning Guidelines present themselves as a mechanism to regulate and discipline the practice of professionals working with infants and toddlers, aiming the integral development of the child. The present article, however, sustains that the role of the educator should not be restricted to an universal pattern, but should instead seek for singularization of children
\end{abstract}

\footnotetext{
Artigo recebido em 10 de Novembro de 2016 e aprovado em 22 de Março de 2017.

${ }^{1}$ Psicanalista, Mestre em Psicologia pela UFMG, Professora universitária, Belo Horizonte, MG, Brasil. Email: vialvim@hotmail.com

${ }^{2}$ Pós-Doutorado em Teoria Psicanalítica (UFRJ), Doutorado e Mestrado em Educação (UFMG), Graduação em Psicologia (UFMG), Professora Adjunta do Departamento de Psicologia e do Programa de Pós-Graduação em Psicologia da UFMG, Belo Horizonte, MG. Email: nadia.laguardia@gmail.com
} 
Keywords: Babies. Infants and toddlers. Education. National Learning Guidelines for small children.

\section{Introdução}

$\mathrm{Na}$ atualidade, a prática do professor de bebês e crianças pequenas nas instituições de educação encontra-se afetada pelo discurso pedagógico, sustentado a partir das legislações e dos referenciais curriculares que apontam parâmetros a serem seguidos pelos profissionais, com o objetivo de garantir a qualidade da educação oferecida às crianças e, consequentemente, o seu desenvolvimento em relação aos aspectos: biológicos, psicológicos, sociais e culturais.

Posto isto, podemos pensar que o discurso pedagógico em vigor na atualidade sobre a escolarização de pequenas crianças segue em direção à promoção de um ideal, no que diz respeito ao exercício da função dos professores de crianças de zero meses aos três anos de idade, dando consistência à noção de competência e oferecendo a certeza no lugar da incerteza. Nesse sentido, vale questionar os efeitos que este discurso pode ter no fazer dos professores.

Calligaris (1994) ressalta o quanto a educação tem partido à procura de um ideal ao qual o sujeito possa se enquadrar. O que possibilita a retirada da educação do campo de práticas onde a subjetividade seja também um ponto a ser tocado, destinando aos profissionais da educação infantil o exercício de uma prática cunhada em um ideal pedagógico sob a lógica do racional.

Do lado da pequena criança, as contingências impostas pela contemporaneidade permitem que elas cheguem cada vez mais cedo às instituições de educação, passando do cuidado individualizado de suas residências a um cuidado coletivizado e amparado pelo ideal pedagógico de nossos tempos. Em um momento no qual estão relacionadas educação e constituição do sujeito, o sujeito se vê impulsionado a deixar o individual em prol do coletivo.

Estudos em Psicanálise apontam que é possível que os bebês e crianças pequenas apresentem problemas que não se restringem a questões orgânicas, mas que podem ser relativos à constituição psíquica do sujeito e ao modo como tal constituição incide no funcionamento das funções orgânicas. (JERUSALINSKY, 2002; LASNIK, 1997). Desta maneira, os profissionais que atuam na educação infantil também passam a ser peça importante na construção da subjetividade da pequena criança. E as instituições de educação infantil passam a atuar, além das frentes pedagógicas e sociais, na subjetividade de bebês e crianças pequenas, ampliando o trabalho feito pela família. 
Para Lajonquière (1999), o ato de educar significa transmitir marcas simbólicas que permitam à criança conquistar para si um lugar na história, onde lhe seja possível o usufruto do desejo. Desta maneira, Lajonquière (1992) argumenta que educar está para além dos métodos pedagógicos, sendo importante considerar que o ato de educar está no Outro. Nenhuma produção subjetiva ou produto da atividade humana podem ser pensados como acontecendo fora do campo do Outro. A aprendizagem e a construção do conhecimento socialmente compartilhado tornam-se possíveis no interior desse campo.

Lajonquière (1999) afirma, ainda, que o que toca a criança não é o conhecimento em si, mas aquele que se dirige a ela, o professor, tal como pontua Freud em Sobre a Psicologia do escolar (1914/1996). Assim, diz Lajonquière (1999, p. 123) que:

\begin{abstract}
Quando ensinamos algo a uma criança, colocamos, por um lado, em ato, nossa fantasmática, isto é, a iniciativa do ato cai na conta do desejo do adulto em função educativa. Por outro lado, transmitimos uma lógica operativa que transcende o campo fantasmático no interior do qual estamos singularmente tomados como sujeitos desejantes, uma vez que se trata de um pedaço da cultura, um universal, um fragmento de liame social. Em suma, à medida que a criança 'apre(e)nde', a amostra de laço transmitida faz um laço que sujeita a criança.
\end{abstract}

Com isto, podemos dizer que a especificidade do fazer do professor da educação infantil exige que sua prática educativa seja reconsiderada, reconhecendo a presença, nesse processo, da subjetividade dos sujeitos implicados - o professor e a pequena criança. Uma compreensão mais ampla dos processos educacionais que ocorrem na Educação Infantil indica que o encaminhamento das situações cotidianas depende do Outro do professor, sendo preciso o reconhecimento do valor das ações docentes no processo de construção da subjetividade da criança. Um desafio que se apresenta nesse percurso da docência do professor de crianças pequenas é o de possibilitá-lo a autoria do seu fazer docente. Ou seja, a construção de uma docência autêntica, animado muito mais por sua sensibilidade e por um fazer artesanal do que pelas certezas pedagógicas já consolidadas e postas sobre ele.

Refletir sobre as legislações e sobre o Referencial Curricular Nacional para a Educação Infantil, no contexto das políticas públicas para a educação infantil, torna-se importante para pensar o fazer do professor de bebês e crianças pequenas. Assim, para fazer tal análise, inicialmente citaremos as modificações que ocorreram nas legislações destinadas à criança e que permitiram a formulação do referencial. Em seguida, 
analisaremos pontos do Referencial Curricular Nacional para a Educação Infantil (RCNEI) e das Diretrizes Curriculares Nacionais para a Educação Infantil (DCNEI) que afetam o fazer do professor da pequena criança, apresentando as tendências e os ideais que orientam a sua prática, como também uma reflexão sobre o lugar do educador e da criança na atualidade, a partir das contribuições da Psicanálise.

\section{A legislação}

Analisar criticamente os referenciais e as diretrizes que regulamenta a educação infantil no Brasil, na atualidade, requer fazer uma breve retrospectiva histórica, desde a promulgação da Constituição Federal de 1988, à criação do Estatuto da Criança e do Adolescente de 1990, até a Lei de Diretrizes e Bases da Educação Nacional $\mathrm{n}^{\circ}$ 9.394/1996. Isto porque foi a partir das deliberações encaminhadas nessas leis e das suas consequências para a área da Educação, que os desafios e as perspectivas para a atuação do professor têm sido apresentados.

Vale apontar que a Lei de Diretrizes da Educação Nacional de 1996 (LDB), que possui como embasamento a Constituição de 1988, foi a responsável por reconhecer como direito da criança pequena o acesso à educação infantil em creches e pré-escolas. Essa lei permitiu que a criança fosse tomada como um sujeito de direitos, em vez de tratá-la, como acontecia nas leis anteriores a esta, como objeto de tutela. Nesta mesma direção, a LDB também pela primeira vez na história das legislações brasileiras proclamou a educação infantil como dever do Estado e como direito das crianças de 0 a 6 anos. Isto é, todas as famílias que escolherem compartilhar com o Estado a educação e o cuidado de seus filhos deverão ser contempladas com vagas em creches e pré-escolas públicas.

Assim, o atendimento em centros de educação infantil como direito social das crianças se afirma na Constituição de 1988 e passa a ser um dever do Estado. O processo que resultou nessa conquista contou com a participação de vários movimentos sociais, dentre eles, podemos citar: os movimentos das mulheres, os movimentos de trabalhadores, os movimentos de redemocratização do país, além das lutas dos próprios profissionais da educação.

Desde então, a educação infantil vivencia um intenso processo de elaboração e reelaboração sobre o entendimento do que constitui a educação de crianças pequenas em espaços coletivos, e de seleção e construção de práticas pedagógicas que possibilitem a aprendizagem e o desenvolvimento das crianças. Em especial, têm se mostrado 
prioritárias as discussões sobre como orientar o trabalho junto às crianças de até três anos nos centros de educação infantil.

Outro ponto proclamado pela lei é o de que as instituições de educação infantil creches e pré-escolas - deverão compor à educação básica, junto com o ensino fundamental e o ensino médio, contrariamente ao que acontecia no passado quando elas eram ligadas às secretarias de assistência social. Esta transição das creches para as secretarias de educação dos municípios foi articulada à compreensão de que estas instituições educacionais têm por funções educar e cuidar, de forma indissociável e complementar, as crianças de zero a seis anos. Anteriormente, as posições das instituições em relação às propostas de trabalho com as crianças pequenas se dividiam entre "assistir e educar". As críticas em relação à inexistência de uma política educativa que orientasse o trabalho com as crianças de 0 a 6 anos, nas instituições, levaram à busca de uma proposta que viesse atender às especificidades desse trabalho - de educar e cuidar - desfazendo qualquer hierarquização do trabalho a ser realizado: tanto pela faixa etária, quanto pelo tempo de atendimento na instituição, ou pelo nome dado à instituição.

Desta maneira, a compreensão da especificidade do caráter educativo das instituições de educação infantil foi historicamente construída, já que ela decorreu de movimentos organizados por diferentes segmentos sociais, por educadores e pesquisadores, em defesa dos direitos da mulher, da criança e do adolescente, em razão das grandes transformações sofridas pela sociedade em geral e pela família, em especial, nos centros urbanos, com a entrada das mulheres no mercado de trabalho. (CERISARA, 1999).

A expectativa era de que a versão final da Lei de Diretrizes e Bases para a Educação, ao passar as instituições destinadas ao cuidado de crianças para a esfera educacional, pudesse avançar, tanto no alcance de um trabalho com características educativo-pedagógicas adequado às especificidades das crianças de zero a seis anos de idade, quanto na formação profissional dos educadores dessas crianças, que passam a ter direito à formação acadêmica. (CERISARA, 1999).

Do lado dos profissionais da educação infantil, a lei estabeleceu que todas os profissionais devem ter formação em nível superior, podendo ser aceita formação em nível médio, na modalidade normal. Ou seja, os profissionais que atuam diretamente com crianças nos centros educacionais, sejam eles denominados auxiliares de sala, 
pajens, auxiliares do desenvolvimento infantil, ou tenham qualquer outra denominação, serão considerados professores e deverão ter formação específica na área. A formação deve ocorrer em cursos de licenciatura, de graduação plena em universidades e em institutos superiores de educação. Se, por um lado, a deliberação sobre a necessidade de formação específica em nível superior dos professores de educação infantil pode ser vista como um avanço na direção da profissionalização, por outro lado, este avanço é relativo, tal como veremos ao longo desse artigo.

Entretanto, existe um aspecto importante a ser ressaltado, que é a inconsistência na especificidade do trabalho do professor de educação infantil, com crianças dos zero aos três anos de idade, nos documentos e nas resoluções analisados. Essa inconsistência na legislação leva o professor a ter como parâmetro, para o seu trabalho, a docência nas séries iniciais do ensino fundamental. É preciso reconhecer que o trabalho com crianças pequenas é bastante diferente daquele com crianças nas séries iniciais do fundamental. Essas especificidades precisam ser analisadas para que o educador possa ajudar efetivamente as crianças pequenas nas instituições educativas.

\subsection{O Referencial Curricular Nacional para a Educação Infantil}

O Referencial Curricular Nacional para a Educação Infantil (RCNEI) ${ }^{3}$ é um documento produzido pelo Ministério da Educação e do Desporto (MEC), que integra a série de documentos Parâmetros Curriculares Nacionais. Se por um lado, podemos considerar um avanço para a Educação a existência de um documento voltado especificamente para a educação infantil, por outro, é necessário perceber até que ponto este documento efetivamente aborda a especificidade do trabalho realizado com crianças dos zero aos três anos de idade em instituições educativas - creches e préescolas, e, além disto, se este documento contempla, na prática do professor, as questões que envolvem a subjetividade da pequena criança e a do próprio professor.

O RCNEI foi organizado em três volumes, sendo o volume 1 intitulado Introdução, o volume 2 Formação pessoal e social, e o volume 3 Conhecimento do mundo. A leitura dos três volumes permitiu constatar que o texto é organizado e bem cuidado esteticamente, acompanhado de belas fotografias e desenhos, contemplando a diversidade cultural das crianças brasileiras. O primeiro volume descreve o objetivo do referencial:

\footnotetext{
${ }^{3}$ Daqui para frente iremos nos referir ao Referencial Curricular Nacional para Educação Infantil pela sua sigla RCNEI.
} 
Sua função é contribuir com as políticas e programas de educação infantil, socializando informações, discussões e pesquisas, subsidiando o trabalho educativo de técnicos, professores e demais profissionais da educação infantil e apoiando os sistemas de ensino estatuais e municipais. (RCNEI, 1998, p. 13).

O volume 1, intitulado Introdução, apresenta noções e temas básicos que permitem delimitar a especificidade da educação infantil no campo da Pedagogia. São eles: criança, educar, cuidar, brincar, relações creche-família, professor de educação infantil, educar crianças com necessidades especiais, instituição e o projeto educativo. Aborda ainda as condições internas e externas à instituição, com destaque para a organização do espaço e do tempo, a importância da parceria com as famílias, entre outros aspectos.

No início do volume 1 , destacamos a referência feita à criança, com ênfase em seu processo de desenvolvimento humano, em diferentes contextos sociais e culturais, ressaltando suas capacidades intelectuais, artísticas, criativas e expressivas. É importante destacar que a prioridade dada à criança deixa em segundo plano a instituição, invertendo a posição hierárquica tradicional que impõe, de cima para baixo, os conteúdos escolares. Entretanto, o tópico "Organização do Referencial Curricular Nacional para a educação infantill, antecipa uma concepção de educação infantil muito mais próxima da concepção do ensino fundamental, pois divide o trabalho a ser realizado com as crianças em: “objetivos gerais e específicos, conteúdos e orientações didáticas, apontando para uma perspectiva de operacionalização do processo educativo". (REFERENCIAL CURRICULAR NACIONAL PARA A EDUCAÇÃO INFANTIL, 1998, p. 43).

O segundo volume, nomeado como Formação pessoal e social, aborda os processos de construção da identidade e autonomia das crianças, e o terceiro, intitulado Conhecimento do mundo, apresenta seis sub-eixos, que são: música, movimento, artes visuais, linguagem oral e escrita, natureza e sociedade e matemática. Estes sub-eixos foram construídos a partir de uma estrutura comum, na qual são colocados os conteúdos a serem trabalhados pelos professores de acordo com a faixa etária das crianças (zero a três anos e quatro a seis anos), as práticas relacionadas aos eixos, os objetivos, as orientações didáticas, as orientações gerais para o professor e a bibliografia.

Podemos perceber como a organização e os conteúdos propostos para os três volumes do RCNEI apontam para um fazer do professor de crianças pequenas subordinado a uma prática pedagógica da didatização, deixando de lado outras 
especificidades do trabalho com crianças pequenas. No momento em que está em jogo para a criança a sua constituição subjetiva, o que parece ser proposto pelo referencial é um cerceamento de sua identidade e autonomia, através de práticas didáticas que utilizam a música, as artes, a linguagem e o movimento, entre outros, para alcançar certo ideal de desenvolvimento às custas de um aprisionamento do corpo pulsional.

O que é sugerido para educação infantil das crianças de zero a três anos de idade parece não diferir dos objetivos propostos para o ensino fundamental, que visa, com seus currículos e conteúdos, que a criança adquira determinadas competências. Nota-se que os desenvolvimentos físico, cognitivo, cultural e de potencialidades da criança aparecem, com frequência, como objetivos do processo de educação infantil. Nos termos do referencial, buscam-se atividades que visam garantir o processo educacional para as crianças pequenas na instituição.

O que observarmos no referencial é que, aquilo que poderia abarcar a subjetividade da criança, é rapidamente capturado por orientações didáticas e transformado em aprendizagem. Assim, a imitação, o brincar, a linguagem e a apropriação da imagem corporal, devem garantir à criança determinadas "aprendizagens", tais como: a satisfação de suas necessidades, a familiarização com a imagem do próprio corpo, o interesse pelo cuidado com o próprio corpo e o relacionamento com as outras crianças e com os seus professores, demonstrando suas necessidades e interesses. Quando o referencial toca em pontos que poderiam ser relacionados à constituição do sujeito - expressão da sexualidade, construção de vínculos e processos de fusão e diferenciação - o documento trata-os como temas necessários para garantir a identidade e a autonomia da criança. (BRASIL, 1998, v.2).

Em relação ao professor de educação infantil o que encontramos no RCNEI, é a figura de um profissional que disponibiliza de forma didática condições para que a criança organize de forma pessoal e independente suas emoções, sentimentos, conhecimentos e regras sociais, brincando de maneira espontânea e prazerosa:

É preciso que o professor tenha consciência que na brincadeira as crianças recriam e estabilizam aquilo que sabem sobre as mais diversas esferas do conhecimento, em uma atividade espontânea e imaginativa [...]. Pode-se, entretanto, utilizar jogos, especialmente aqueles que possuem regras, como atividades didáticas. É preciso, porém, que o professor tenha consciência que as crianças não estarão brincando nestas situações, pois há objetivos didáticos em questão. (BRASIL, 1998, p. 29, v. 1).

Ao professor é colocada a função de mediar - as crianças e o conhecimento - e de intervir quando necessário. Isto para que os alunos, em interação com os outros 
alunos ou sozinhos, possam ampliar as capacidades de apropriação de conceitos, códigos sociais, diferentes linguagens, experimentação, reflexão, elaboração de perguntas e respostas e construção de objetos e brinquedos. Assim, o professor deve apenas manter os meios para que a brincadeira aconteça, já que os alunos aprendem espontaneamente e em interação com os seus pares. Ele deve, ainda, propiciar situações e espaços de aprendizagem, que articulem os recursos e capacidades afetivas, emocionais, sociais e cognitivas aos conhecimentos prévios da criança e aos conteúdos referentes aos diferentes campos de conhecimento humano, levando em consideração as particularidades das crianças em diferentes idades. Como, também, levando em consideração a diversidade social, étnica e de costumes e valores presentes na sala de aula, trabalhando com o respeito às diferenças e promovendo a socialização. $\mathrm{Na}$ instituição de educação infantil, o professor constitui-se, portanto, no parceiro mais experiente por excelência, cuja função é propiciar e garantir um ambiente rico, prazeroso, saudável e não discriminatório de experiências educativas e sociais variadas (BRASIL, 1998, v. 2).

Ora, ainda que o professor seja definido como o parceiro mais experiente entre as crianças sua função recai na de um "organizador" das atividades em sala, a partir das experiências e conhecimentos das crianças. A presença do professor tem efeitos para uma criança e ainda que sua função difira da função materna e da função paterna, seu trabalho porta algo da transmissão e do desejo.

Rocha (1999), em sua pesquisa, intitulada A Pesquisa em Educação Infantil no Brasil: Trajetória Recente e Perspectivas de Consolidação de uma Pedagogia, busca alcançar meios para a construção de um campo particular na área da Pedagogia para crianças, distinguindo a educação infantil da escolar, a partir da contribuição destes diferentes campos científicos: Educação, Ciências Sociais, História, Psicologia. Para a autora, a pedagogia da infância traz, em primeiro lugar, uma preocupação predominante com a criança em detrimento de sua escolarização. Fato este que acarretará uma nova proposta que possui o intuito de diferenciar a educação infantil da educação escolar, esta última sendo função do ensino fundamental e não do nível responsável pelas crianças de 0 a 6 anos. A autora considera, ainda, que a Pedagogia deve tomar como ponto principal para a construção desta proposta as diferentes infâncias existentes, defendendo a ideia de uma educação que leve em consideração a multiplicidade de sujeitos e suas diferentes infâncias para planejar as condições educacionais da instituição e, além disso, 
dar importância aos diversos tempos que cada um exige, respeitando as particularidades de cada criança. Assim, a autora defende a construção desta ciência da Educação a partir da capacidade de refletir sobre a prática, visando à construção de saberes que instrumentalizarão a própria ação.

Tomando como eixo principal da discussão sobre a educação infantil a questão da subjetividade, consideramos que a tentativa de se apreender o desenvolvimento infantil através de projetos pedagógicos completos e universais será sempre fracassada. É preciso que o trabalho do professor seja descaracterizado de conteúdos e afetado por outros saberes sobre a infância, como pondera Rocha (1999), mas é preciso ainda deixar uma brecha para o não-saber, para o impossível de apreender, para o vazio de conhecimentos, para que seja possível a emergência de um saber construído pela própria criança.

Para Rocha (1999), o professor deve ser descaracterizado enquanto tal, já que, não tem por função ensinar, característica basilar de sua profissão. Sua prática pedagógica deve ser estruturada de maneira a atender aos cuidados infantis e as especificidades da educação infantil. Ao mesmo tempo, alerta que o professor não pode ser visto como um mentor ou mesmo dirigente da prática educativa, tendo que agir em uma perspectiva dialógica, organizando a prática educativa na instituição de acordo com os desejos da clientela atendida, desta maneira, são as crianças que ditam as regras na estruturação do planejamento educacional. Desta maneira, a autora retira do professor a função de um simples organizador que auxilia a criança a desenvolver seu intelecto e o coloca no lugar de estar atento às singularidades de cada criança. (ROCHA, 1999).

A mesma autora confere às instituições de educação infantil a função de dar continuidade à educação fornecida pelas famílias, levando em consideração as diferentes esferas do conhecimento científico além do campo da educação, tendo o professor que estar apto a lidar com conhecimentos advindos da área nutricional, da saúde, proporcionar afetividade, compensação familiar.

Rocha (1999) considera, ainda, que o educador tem a responsabilidade de complementar os trabalhos de cuidado e formação da criança iniciados pela família, incluindo a saúde, a nutrição, a compensação familiar, a afetividade e o sanitarismo. Os seus apontamentos são interessantes, pois delineiam uma prática do educador que sai do campo meramente didático e abre espaço para abarcar outros saberes, além da afetividade, fornecendo um apoio e uma complementação à família. Mas, essa 
ampliação de conhecimentos, que ele sugere, pode se tornar uma sobrecarga de difícil assimilação para o professor e pode culminar num currículo tão aprisionante para o sujeito, quanto qualquer outro. Talvez o fundamental seja reconhecer, na função do professor, um espaço de não-saber sobre cada criança. É a partir desse não-saber que o professor pode oferecer uma atenção individualizada a cada bebê e criança pequena, buscando aproximar de cada criança como única, para localizar o que lhe é próprio, a sua forma particular de se manifestar, de interagir com o outro, os seus interesses específicos, o que lhe dá prazer e o que lhe angustia. É a partir do interesse do educador por cada criança, individualmente, que ele descobre o seu fazer de professor, que só pode ser planejado tomando cada criança em sua particularidade. Assim, não é que ele não deva assumir um lugar de autoridade ou de educador, pois, na posição de adulto que ele ocupa, ele não pode se equivaler à criança. O importante é que ele reconheça cada criança como um sujeito que, em razão de estar situada num tempo lógico de alienação ao Outro, precisa de um Outro encarnado que lhe ofereça, para além dos cuidados físicos e educativos, um lugar específico no seu desejo.

Podemos, então, notar que os três volumes do RCNEI (1998) operam com preceitos pedagógicos da educação voltados para o aprendizado e o conteúdo, ainda que a tentativa tenha sido - como anuncia o próprio referencial - a de encontrar as especificidades do trabalho do professor com crianças de zero a seis anos de idade. Entretanto, o RCNEI (1998), em seus três volumes, não se configura como um documento mandatório ou obrigatório e deve ser lido como um material entre tantos outros que podem servir para os professores refletirem sobre o trabalho a ser realizado com as crianças de 0 a 3 anos em instituições coletivas de educação e cuidado públicos. Ou seja, nenhuma instituição ou sistema de ensino deve se subordinar ao RCNEI a não ser que opte por fazê-lo. Como orientação nacional a área dispõe as Diretrizes Curriculares Nacionais para Educação Infantil (2010) que apresentam as diretrizes obrigatórias a serem seguidas por todas as instituições de educação infantil no país.

\subsection{Diretrizes Curriculares Nacionais para Educação Infantil}

A Resolução $\mathrm{n}^{\circ}$ 5, de 17 de dezembro de 2009, determina as Diretrizes Curriculares Nacionais para a Educação Infantil. Esta norma tem por objetivo estabelecer as Diretrizes Curriculares Nacionais para a Educação Infantil (DCNEI, 2010) a serem observadas na organização de propostas pedagógicas para a educação 
infantil. Assim, as Diretrizes Curriculares Nacionais para a Educação Infantil articulamse às Diretrizes Curriculares Nacionais da Educação Básica (2013) e reúnem princípios, fundamentos e procedimentos definidos pela Câmara de Educação Básica do Conselho Nacional de Educação, para orientar as políticas públicas e a elaboração, planejamento, execução e avaliação de propostas pedagógicas e curriculares de Educação Infantil. Além das exigências dessas diretrizes, devem, também, ser observada a legislação estadual e municipal atinentes ao assunto, bem como as normas do respectivo sistema.

As diretrizes definem que os fundamentos norteadores para as propostas pedagógicas das instituições de educação infantil devem respeitar princípios éticos, políticos e estéticos definidos pelo documento.

Neste documento, Diretrizes Curriculares Nacionais da Educação Básica (2013), a criança é definida como um sujeito histórico e de direitos, que nas relações e interações do dia-a-dia constrói sua identidade pessoal e coletiva, brinca, imagina, fantasia, deseja, aprende, observa, experimenta, narra, questiona e constrói sentidos sobre si e sobre a sociedade, produzindo cultura. Já o currículo para a educação infantil é definido como uma rede de práticas que visam articular as vivências e os saberes das crianças com os conhecimentos que fazem parte do patrimônio cultural, científico, ambiental e tecnológico, de maneira a possibilitar o desenvolvimento integral da criança de zero aos cinco anos de idade. (BRASIL, 2010).

Sendo assim, estas instituições devem ter como objetivo uma proposta curricular pedagógica que garanta para a criança:

\footnotetext{
O acesso a processos de apropriação, renovação e articulação de conhecimentos e aprendizagens de diferentes linguagens, assim como o direito à proteção, à saúde, à liberdade, à confiança, ao respeito, à dignidade, à brincadeira, à convivência e à interação com outras crianças. (BRASIL, 2010, p. 18).
}

As Diretrizes Curriculares Nacionais para Educação Infantil apresentam objetivos gerais e definições sobre a criança, à educação infantil e o currículo sem ir ao detalhe de cada ação como o RCNEI. Assim, elas possibilitam a construção de propostas para a educação infantil de crianças dos zero aos três anos de idade nos níveis mais diretos da atuação, deixando um espaço para que os envolvidos na educação infantil - famílias, professoras e crianças - assumam a autoria desses projetos.

São pontos também abordados pelas diretrizes: os procedimentos de matrícula por faixa etária, a jornada escolar que deve ser de no mínimo quatro horas e em tempo integral com duração igual ou superior a sete horas, os processos de avaliação do 
trabalho e os eixos curriculares que devem constar no currículo da educação infantil. Porém, o que achamos importante destacar é que neste documento é posto, ao final, que ainda encontra-se em debate alguns temas para a formulação de orientações curriculares, dentre eles: "As especificidades da ação pedagógica com os bebês". (BRASIL, 2010, p. 31).

Se, por um lado o RCNEI apresenta propostas que nomeamos de didatizantes para o trabalho do professor com crianças dos zero aos três anos de idade, por outro, as DCNEI de 2010, deixam em aberto o debate sobre o fazer do professor com a pequena criança. Assim, podemos pensar que a prática do professor de crianças pequenas é afetada, tanto pelo Outro do referencial, que coloca metas ao fazer do professor, quanto pelo Outro das diretrizes, que estabelece normas, mas que também coloca seu fazer em debate, possibilitando que o professor se interrogue sobre sua prática a partir de um não saber sobre o seu fazer.

\subsection{O Biopoder e a Educação Infantil}

O estudo dos referenciais e das diretrizes para a educação infantil nos permitiu constatar que existe uma relação entre a legislação no campo da educação e o conceito de biopoder desenvolvido por Foucault (1988). É disto que, por ora, vamos nos ocupar, para analisar os efeitos das técnicas apontadas pelos instrumentos que regulam o trabalho do professor de crianças pequenas nas instituições de educação infantil.

O conceito de biopoder foi desenvolvido por Foucault (1988) em uma de suas mais notórias obras, A história da sexualidade, sendo o primeiro volume publicado em 1976. Esse conceito pode ser um importante instrumento nas reflexões acerca das práticas disciplinares presentes na sociedade contemporânea. Os referenciais e legislações construídos para a educação infantil apresentam-se como uma maneira de regular e disciplinar a atuação dos profissionais da educação infantil, a fim de que seja garantido à criança o seu desenvolvimento integral.

O biopoder constitui-se como uma forma de poder que se exerce sobre a vida, com o objetivo de geri-la e aumentar-lhe as forças, dividindo-se em dois polos: o da disciplina - que investe sobre a vida dos corpos individuais - e o da biopolítica das populações - que investe sobre a vida da espécie. O polo disciplinar possui, como recurso fundamental, a vigilância. O polo biopolítico utiliza, principalmente, os 
controles reguladores de aspectos da vida das populações, dentre eles: suas taxas de natalidade, de saúde, de morbidade, de envelhecimento e de mortalidade.

Podemos dizer que a emergência desta forma de poder produziu vários efeitos sobre a educação, dentre eles, a pedagogização e a didatização de múltiplos aspectos da vida da criança, que buscam garantir à criança o seu pleno desenvolvimento físico e cognitivo. A representação de criança sustentada pelo referencial é a de um ser em desenvolvimento que precisa ser despertado e impulsionado pelo educador. Essa concepção de criança não equivale à concepção psicanalítica, que pressupõe, na criança, um sujeito dividido e desejante, e que, portanto, não apresenta um desenvolvimento linear e programável.

O biopoder surge nas sociedades disciplinares que emergiram entre os séculos XVII e XVIII e tiveram seu ápice com os campos de concentração nazista. Estas sociedades pautavam-se em uma tecnologia política do corpo destinada a extrair, destes, docilidade política e utilidade econômica. (FOUCAULT, 1988).

Esta forma de poder é considerada, por Foucault (1988), como um poder totalizante e simultaneamente individualizante, marcado pelas grandes instituições disciplinares - escolas, hospitais, fábricas e prisões - e também por investimentos individuais para incitar a maior produtividade dos corpos. Entretanto estes dispositivos não sugiram apenas para garantir a manutenção das relações de produção e dos processos econômicos, mas apareceram como uma forma de sustentação dos poderes.

Assim, Foucault (1988), considera que o biopoder colocar o poder num papel central nas sociedades. Nas sociedades soberanas, a figura central, o soberano, possuía o monopólio da violência, ou seja, ela possuía o direito sobre a vida de seus súditos. A vida do súdito ficava em perigo quando este se tornava uma ameaça ao poder do soberano. Portanto, neste tipo de relação o poder se estabelecia em uma relação direta com a vida.

Contrariamente ao ocorrido nas sociedades soberanas, nas sociedades disciplinares o poder sobre a vida não está direcionado à possibilidade de extinção desta. O biopoder surge como um meio de controle da vida em toda sua amplitude, de modo que busca organizá-la, vigiá-la, com o objetivo de controlá-la, através dos aparelhos de produção capitalista. (FOUCAULT, 1988).

Para Foucault (1988), a disciplina direcionada para o indivíduo tem como objetivo o controle de seu corpo e sua consequente normatização e adestramento, 
através das instituições modernas presentes na vida do indivíduo, facilitando a integração do indivíduo em sistemas de controle mais eficazes e com menor custo de produção. Desta maneira, estas instituições domesticam os corpos tornando-os aptos ao trabalho industrial. O poder disciplinador age sobre os corpos através de sua integração a espaços determinados, do controle do tempo sobre os corpos, da vigilância constante e, também, da produção do conhecimento.

Se o poder disciplinar age sobre os indivíduos no controle do seu corpo, paralelamente a ele, Foucault (1988) descreve a biopolítica, uma forma de controle que age em um âmbito mais amplo: a espécie. Ou seja, ela atua no controle dos processos de nascimento e de morte, da saúde da população, da longevidade, dentre outros.

Desta maneira, o biopoder pode ser compreendido como um mecanismo de controle da vida em um âmbito geral, isto é, a ação do poder disciplinador sobre o biológico que, nesse contexto, ganha papel central nas questões políticas. Tendo como um de seus objetivos transformar e aperfeiçoar as formas de controle sobre a vida, visando sempre um maior poder sobre a espécie.

Podemos, pois, compreender o biopoder como uma forma de controle sobre a população, os indivíduos são tomados através de seu valor e utilidade para o processo de produção a sociedade capitalista. Tal poder é estabelecido como forma de normatização das condutas dos corpos e da vida através dos diversos aparelhos presentes na sociedade, como, por exemplo, os professores, a legislações e as diretrizes para educação infantil.

Para Foucault (1988), este é um processo que submeteu a vida às tecnologias do poder. Ele permite que a vida seja compreendida como um objeto, e deste modo, o direito sobre ela, sobre o corpo, sobre o ser vivo, tornou-se uma questão de primeira ordem, no âmbito político:

O que é reivindicado e serve de objeto é a vida, entendida como as necessidades fundamentais, a essência concreta do homem, a realização de suas virtualidades, a plenitude do possível. Pouco importa que se trate ou não de utopia: temos aí um processo bem real de luta; a vida como objeto político foi de algum modo tomado ao pé da letra e voltada para o sistema que tentava controlá-la. (FOUCAULT, 1988, p.158).

Se a educação é compreendida pelo Referencial Curricular Nacional para a Educação Infantil (1998, p. 23, v.1) como um processo que possibilita “o desenvolvimento das capacidades de apropriação e conhecimento das potencialidades corporais, afetivas, emocionais, estéticas e éticas, na perspectiva de contribuir para a 
formação de crianças felizes e saudáveis" podemos dizer que ela atua, como na biopolítica descrita por Foucault (1988), como um modo de regulamentação da vida e controle da população. Neste sentido, podemos compreender as políticas educacionais como ações direcionadas para a população, de forma racional, onde há uma série de técnicas utilizadas como forma de controle das condutas individuais e coletivas - tanto do lado dos professores, quanto do lado da pequena criança.

A biopolítica faz com que surja um novo corpo múltiplo denominado população. Esta passa a ser lidada como um problema político, sendo que a junção da ciência com a política torna-se análoga à problematização do biológico num campo de poder. Assim, a natureza dos fenômenos é transferida do indivíduo para o coletivo. (FOUCAULT, 2000).

Um terceiro ponto a ser destacado é o fato dessa tecnologia de poder, essa biopolítica, constituir-se de mecanismos com funções de previsão, estimativas estatísticas, medições globais, o que provocará implicações para: a modificação da morbidade, o alongamento da vida e o estímulo à natalidade. Para tanto, os mecanismos reguladores devem fixar equilíbrios, manter as médias, assegurar compensações, ou seja, construir ideais para um estado de vida. Assim como os mecanismos disciplinares devem maximizar as forças e extraí-las para um melhor aproveitamento, a biopolítica deve assegurar uma regulamentação. (FOUCAULT, 2000).

Pode-se, agora, entender como os mecanismos de poder político passaram, no século XX, a legislar e controlar a vida, a sua produção, bem como a produzi-la, tendo como base o biopoder ou as técnicas políticas sobre ela. O poder desloca-se daquele sobre a morte e passa a agir positiva e contrariamente sobre a vida; a sua gestão, a sua administração e a sua regulamentação exaltam o caráter de preservação da vida, ou seja, gerir a vida em termos biológicos, eliminando aqueles que se colocarem contra tal prerrogativa. (FOUCAULT, 2000).

É possível, portanto, articular a descrição de Foucault da biopolítica com a teoria psicanalítica. A abordagem psicanalítica caminha na contramão ao que vem sendo traçado no campo da educação infantil, colocando a função do professor no campo da transmissão, para além de cuidados técnicos. Sendo assim, o fazer do professor na educação infantil não se reduziria a técnicas de ensino ou a métodos pedagógicos passíveis de universalização. O trabalho na educação infantil postularia na esfera dos laços afetivos com um caráter artesanal, contemplando a singularidade das crianças. A 
função do educador, então, caminharia no sentido da construção de um laço singularizado com os bebês e crianças pequenas, sustentando as operações constituintes da subjetividade.

Considerando que os profissionais de educação infantil estão ao lado dos familiares nos cuidados e na educação de bebês e crianças pequenas, assumindo também uma função em sua constituição, entende-se que esses profissionais precisam estar preparados para acompanhar o desenvolvimento das crianças sob seus cuidados e, também, atentos às suas formas de manifestação subjetiva. Para além dos cuidados com a satisfação das necessidades, o educador deve supor, no bebê, um sujeito. $\mathrm{O}$ grande desafio é, portanto, o de fazer pender o equilíbrio para o lado da subjetivação, mais do que para o lado da objetivação.

\subsection{A criança na atualidade}

Como investir planejadamente nos bebês e nas crianças, de forma a fazê-los desenvolverem seu máximo potencial? Esta parece ser a vertente da Pedagogia contemporânea que alimenta os professores em sua formação, governados pelas ciências da educação.

Os bebês e as crianças são um destes objetos da atualidade, a quem se pede que se adapte. Não apenas nos termos de parâmetros para a educação, mas também nos termos de manuais de patologia que classificam os transtornos infantis, a partir das manifestações e características que as crianças apresentam. Assim, sobre eles recai esse Outro todo-onipotente aparelhado e preparado pelas técnicas e manuais oferecidos pelo discurso científico.

$\mathrm{Na}$ atualidade, a forte penetração do discurso da ciência no campo da educação escolar encontra-se fortemente respaldado pela lógica capitalista contemporânea que possui como objetivo principal o consumo, isto é, a busca constante de novos objetos. $\mathrm{O}$ imperativo do consumo não é sem consequências para a educação, que se guia pela lógica de educar para o mercado e para o sucesso, empreitada que atualiza a forma de mal-estar na educação, com crianças sem desejo de aprender, hiperativas, agitadas, anoréxicas, dentre outros sintomas.

Essa reflexão nos leva a analisar o lugar que a criança ocupa na atualidade.

A abordagem freudiana situa a criança como um Ideal do Eu do casal parental Freud [1914]/(1996) e Lacan (2003) a localiza como o objeto $a$ na fantasia materna. Se 
em Freud [1914]/(1996) a expressão "sua majestade o bebê" constitui uma fórmula para situar a criança, localizando o seu lugar e o seu valor na estrutura familiar, Lacan [1969]/(2003), em Nota sobre a criança, refere-se ao sintoma da criança como o que pode responder ao par familiar ou ao objeto do fantasma materno. Assim, o autor aponta que a criança tanto pode ser posta no lugar de substituto fálico para os pais, quanto pode ser colocada no lugar de objeto.

Laurent (2007, p. 44-45) ao discutir a questão do lugar da criança na sociedade atual a situa como objeto $a$ tomada pelo gozo de seus pais, familiares e professores. Assim, argumenta:

A criança é o objeto a, vem no lugar de um objeto, e é a partir disso que a família se estrutura. Ela não se assenta na metáfora paterna, que era a face clássica do complexo de Édipo, e sim na maneira como a criança é o objeto de gozo da mãe, da família, e, para além dela, da civilização. A criança é o "objeto a liberado".

Desta maneira, o autor retoma expressão de Lacan (2008, p. 293) que aponta a criança como "o objeto a liberado" para colocar a criança não só como objeto $a$ da fantasia materna, mas também como objeto de gozo da família, da civilização, o que não é sem consequências para a subjetividade da criança. Laurent (2007) salienta ainda que a criança como objeto $a$ liberado é o que cria a família na atualidade. Se antes era preciso uma família para a criança existir, hoje é o surgimento da criança que a constrói.

Destacada as diferenças que marcam a posição da criança na teoria psicanalítica - da posição de ideal apresentada por Freud, no século passado, à posição objetal da criança frente às figuras parentais na atualidade - pensamos que a criança na sociedade atual é reduzida a objeto do gozo de seus pais, professores e de quem mais se ocupe dela. Muitas vezes, a criança, esvaziada de subjetividade, é condenada a sucumbir como objeto da miséria da sociedade capitalista.

Frente a tais colocações cabe a nós indagarmos como oferecer à criança - seja na família, na escola, nas políticas públicas - outro lugar que não o de objeto do gozo. Arendt (2000, p. 247) aponta uma saída pela via do amor:

A educação é, também, onde decidimos se amamos nossas crianças o bastante para não expulsá-las de nosso mundo e abandoná-las a seus próprios recursos, e tampouco arrancar de suas mãos a oportunidade de empreender alguma coisa nova e imprevista para nós, preparando-as em vez disso com antecedência para a tarefa de renovar um mundo comum.

Apostamos que essa condição só pode ser alcançada a partir de uma posição desejante daquele que conduz o trabalho educativo, que, assumindo a responsabilidade pelo mundo, parte de um não-saber sobre a criança em direção ao singular. 
Assim, podemos concluir que a impossibilidade de se educar na sua plenitude (pois resta sempre uma dimensão ineducável em cada sujeito), a impotência do discurso pedagógico em tudo prever (pois há sempre algo de imprevisível na prática pedagógica) e a flexibilidade e abertura dos regulamentos e das diretrizes curriculares permitem que o professor introduza no processo de educação algo do seu corpo e do seu estilo - algo da sua subjetividade. Sendo assim, é possível construir estratégias e soluções, criando um saber fazer diante dos impasses que surgem na educação e no cuidado com as crianças. Suportar o não saber é uma forma de operar com o seu desejo. Ao oferecer um lugar específico para cada criança em seu desejo, o professor favorece a emergência do sujeito. 


\section{REFERÊNCIAS}

ARENDT, Hannah. Entre o passado e o futuro. 5. ed. São Paulo: Editora Perspectiva, 2000.

CALLIGARIS, Contardo (Org.). Educa-se uma criança?. Porto Alegre: Artes e Ofícios, 1994.

CERISARA, Ana Beatriz. Educar e cuidar: por onde anda a educação infantil? Perspectiva, Florianópolis, v. 17, n. especial, 1999.

BRASIL. Constituição (1988). Constituição da Republica Federativa do Brasil. São Paulo: Saraiva, 1999.

BRASIL. Lei n. 9.394, de 20 de dezembro de 1996. Lei de Diretrizes e Bases da Educação Nacional. Diário Oficial da União, Brasília, 21 de dezembro de 1996.

BRASIL. Ministério da Educação. Secretaria de Educação Básica. Diretrizes Curriculares Nacionais para a Educação Básica. Brasília: MEC/SEB, 2013.

BRASIL. Ministério da Educação. Secretaria de Educação Básica. Diretrizes curriculares nacionais para a educação infantil - DCNEI. Brasília: MEC/SEB, 2010.

BRASIL. Ministério da Educação. Secretaria de Educação Básica. Referencial Curricular Nacional para a Educação Infantil: introdução. v.1. Brasília: MEC/SEF, 1998. Disponível em:< http://portal.mec.gov.br/seb/arquivos/pdf/rcnei_vol2.pdf> Acesso em: 10 de Jan. 2014.

BRASIL. Ministério da Educação. Secretaria de Educação Básica. Referencial Curricular Nacional para a Educação Infantil: formação pessoal e social. v.2. Brasília: MEC/SEF, 1998. Disponível em <http://portal.mec.gov.br/seb/arquivos/pdf/rcnei_vol3.pdf> Acesso em: 10 de Jan. 2014.

BRASIL. Ministério da Educação. Secretaria de Educação Básica. Referencial Curricular Nacional para a Educação Infantil: conhecimento de mundo. v.3. Brasília: MEC/SEF, 1998. Disponível em: http://portal.mec.gov.br/seb/arquivos/pdf/rcnei_vol1.pdf> Acesso em: 10 de Jan. 2014.

FREUD, Sigmund. Sobre o narcisismo: uma introdução. In: FREUD, Sigmund. Edição Standard brasileira das obras psicológicas completas de Sigmund Freud. Rio de Janeiro: Imago, 1914-1916. v.14, 1996.

FOUCAULT, Michel. Em defesa da sociedade: curso no Collège de France (19751976). São Paulo: Martins Fontes, 2000.

FOUCAULT, Michel. Historia da Sexualidade: a vontade de saber. Rio de Janeiro: Edições Graal, 1988.

JERUSALINSKY, Julieta. Enquanto o futuro não vem: a psicanálise na clínica interdisciplinar com bebês. Salvador: Álgama, 2002. 
LACAN, Jacques. Nota sobre a criança. In: LACAN, Jacques. Outros Escritos. Rio de Janeiro: Jorge Zahar Editor, 1969. p. 369-370, 2003.

LACAN, Jacques. O seminário, livro 20: Mais, ainda. Rio de Janeiro: Jorge Zahar Editor, 1968-1969. 2008.

LASNIK, Marie-Christine. Rumo à palavra: três crianças autistas em psicanálise. São Paulo: Escuta, 1997.

LAURENT, Éric. A sociedade do sintoma: a Psicanálise, hoje. Rio de Janeiro: Contra Capa, 2007.

ROCHA, Eloísa A. C. A Pesquisa em Educação Infantil no Brasil: Trajetória Recente e Perspectivas de Consolidação de uma Pedagogia. 1999. Tese (Doutorado) UNICAMP, Campinas. 